\title{
Comparison of the pharmacodynamic profiles of a biosimilar filgrastim and Amgen filgrastim: results from a randomized, phase I trial
}

\author{
Cornelius F. Waller • Miguel Bronchud • Stuart Mair • \\ Rodeina Challand
}

Received: 9 March 2010 /Accepted: 6 April 2010 /Published online: 22 June 2010

(C) The Author(s) 2010. This article is published with open access at Springerlink.com

\begin{abstract}
Further to the patent expiry of Neupogen ${ }^{\circledR}$ (Amgen filgrastim), Hospira has developed a biosimilar filgrastim (Nivestim ${ }^{\mathrm{TM}}$ ) that may offer a clinically effective alternative for multiple hematologic and oncologic indications. Here results are reported from a phase I trial, primarily designed to compare the pharmacodynamic profiles of Hospira filgrastim and Amgen filgrastim. A phase I, single-center, double-blind, randomized trial was undertaken to demonstrate equivalence of the pharmacodynamic characteristics of Hospira filgrastim and Amgen filgrastim. Fifty healthy volunteers were randomized to receive 5 or $10 \mu \mathrm{g} / \mathrm{kg}$ dosing, before further randomization to treatment sequence. All volunteers received five daily subcutaneous doses of Hospira filgrastim or Neupogen, with subsequent crossover to the alternative treatment. Bioequivalence was evaluated by analysis of variance; if the estimated $90 \%$ confidence intervals (CIs) for the ratio of 'test' to 'reference' treatment means were within the
\end{abstract}

\section{F. Waller $(\square)$}

Abt. Innere Medizin I, Medizinische Universitätsklinik,

Hugstetter Strasse 55,

79106 Freiburg, Germany

e-mail: cornelius.waller@uniklinik-freiburg.de

\section{Bronchud}

Hospital General of Granollers,

Avenida Francisco Ribas s/n,

08400 Granollers, Barcelona, Spain

\section{S. Mair}

Charles River Clinical Services,

Tranent, Edinburgh, East Lothian EH33 2NE, UK

\section{R. Challand}

Hospira Ltd, Queensway, Leamington Spa,

Warwickshire CV31 3RW, UK conventional equivalence limits of $0.80-1.25$, then bioequivalence was concluded. Forty-eight volunteers completed the study. Geometric mean absolute neutrophil count area under the curve from time 0 to the last time point at day 5 (primary endpoint) was comparable in volunteers given Hospira filgrastim or Amgen filgrastim at $5 \mu \mathrm{g} / \mathrm{kg}$ (ratio of means, $0.98 ; 90 \% \mathrm{CI}, 0.92-1.05$ ) or $10 \mu \mathrm{g} / \mathrm{kg}$ (ratio, 0.97 ; 90\% CI, 0.93-1.01); 90\% CIs were within the predefined range necessary to demonstrate bioequivalence. Hospira filgrastim was well tolerated with no additional safety concerns over Amgen filgrastim. Hospira filgrastim is bioequivalent with Amgen filgrastim with regard to its pharmacodynamic characteristics.

Keywords Filgrastim · Biosimilar $\cdot$ G-CSF $\cdot$ Neutropenia

\section{Introduction}

Recombinant granulocyte colony-stimulating factor (GCSF; filgrastim) has formed an integral part of supportive therapy across multiple oncologic and hematologic indications under the trade name Neupogen ${ }^{\circledR}$ (Amgen filgrastim; Amgen Inc., Thousand Oaks, CA, USA) [1-3]. Hospira has developed a biosimilar version of filgrastim (Hospira filgrastim, Nivestim ${ }^{\mathrm{TM}}$ ), which could potentially provide a clinically effective alternative to Amgen filgrastim.

The current use of Amgen filgrastim and the early development of Hospira filgrastim have been described previously in this journal as part of a study that demonstrated the bioequivalence of the two filgrastims in terms of their pharmacokinetic (PK) characteristics [4]. This published study was the first of two randomized, phase I trials conducted to compare the properties of Hospira filgrastim and Amgen filgrastim in healthy volunteers. 
Here we report results from the second randomized, phase I trial, which was primarily designed to compare the pharmacodynamic (PD) profiles of Hospira filgrastim and Amgen filgrastim following administration of multiple, consecutive subcutaneous (s.c.) doses at two dose levels (5 or $10 \mu \mathrm{g} / \mathrm{kg}$ ). PK and safety assessments were secondary objectives of the study.

\section{Design and methods}

\section{Eligibility}

The study protocols and all amendments were approved by a local research ethics committee and the UK Medicines and Healthcare Products Regulatory Agency. All volunteers gave written informed consent before any study-specific procedures were undertaken. Volunteers were free to withdraw from the study at any time.

Healthy, non-smoking, male or female volunteers aged $18-50$ years, with a body mass index of $19-30 \mathrm{~kg} / \mathrm{m}^{2}$ and a body weight of $50-110 \mathrm{~kg}$, were recruited. Exclusion criteria were identical to those described for the previously reported phase I PK study of Hospira filgrastim, except for those specifically relating to i.v. drug administration [4]. Concurrent use of prescription or overthe-counter medicines (excluding hormonal contraceptives and occasional use of paracetamol) was not permitted. Similarly, caffeine- and alcohol-containing beverages were not allowed during the assessment periods or in the $24 \mathrm{~h}$ prior to first dose.

\section{Study design and outcomes}

Volunteers were treated at Charles River Clinical Services, Edinburgh, UK, between November 2, 2006 and January 24, 2007, as part of a randomized, double-blind, comparator-controlled, two-way, crossover trial. Volunteers were randomized to one of two dose levels ( 5 or $10 \mu \mathrm{g} / \mathrm{kg}$ ) before further randomization to order of agent administration. An initial screening period of up to 21 days was followed by two 10-day assessment periods, separated by a washout period of at least 13 days. Volunteers received a total of five s.c. injections of Hospira filgrastim (at one of the two doses) or Amgen filgrastim (at a matching dose level) over five consecutive days, at approximately the same time each day, with crossover to the alternative study drug in the second assessment period. Randomization was performed according to a computer-generated randomization list, produced by Constella Group Ltd, Abingdon, UK. Conditions relating to provision of meals, fasting periods, overnight stays, and levels of permitted physical activity were standardized throughout.
The primary endpoint was absolute neutrophil count (ANC) area under the curve from time 0 to the last time point $\left(\mathrm{AUC}_{0 \text {-tlast }}\right)$ at day 5 , while secondary endpoints included $\mathrm{ANC}$ time at which maximum observed plasma concentration $\left(C_{\max }\right)$ occurred $\left(T_{\max }\right), \mathrm{ANC}_{\max }, \mathrm{ANC}_{\text {min }}$, and $\mathrm{CD} 34+$ cell count, also at day 5. Secondary PK endpoints included $C_{\max }$, minimum concentration observed $\left(C_{\min }\right), T_{\max }$, elimination half life $\left(T_{1 / 2}\right), \mathrm{AUC}_{0-\text { tlast }}, \mathrm{AUC}$ from time 0 to $24 \mathrm{~h}\left(\mathrm{AUC}_{0-24 \mathrm{~h}}\right)$, AUC from 0 to infinity $\left(\mathrm{AUC}_{0-\text { infinity }}\right)$, terminal elimination rate constant $\left(\lambda_{\mathrm{z}}\right)$, and clearance for plasma concentration of G-CSF at day 5 . Safety was also assessed.

Blood samples were collected for measurement of plasma G-CSF at $-1 \mathrm{~h}$ on days $1-4$ and at $-1,0.25,0.5$, $0.75,1,2,3,4,6,8,10,12,16$, and $24 \mathrm{~h}$ post dose on day 5 of each assessment period. For PD (ANC) analysis, samples were collected at $-1 \mathrm{~h}$ on days $1-4$ and at $-1,0.5,1,2,4,6$, $8,24,48,72,96$, and $120 \mathrm{~h}$ following dose administration on day 5 . For determination of CD34+ cell counts, samples were collected on days 1 (predose), 3 ( $6 \mathrm{~h}$ post dose), 5 ( $6 \mathrm{~h}$ post dose), 7 (48 h post dose), and 10 (120 h post dose). GCSF concentrations were assessed by the Charles River Laboratories Central Laboratory using a validated commercial assay [5-9]. CD34+ cell counts were determined in the same laboratory using a commercial flow cytometry kit (Stem-Kit ${ }^{\mathrm{TM}}$, Beckman Coulter, High Wycombe, UK) that was validated in house. Cells were labeled using a phycoerythrin-conjugated anti-CD34 monoclonal antibody, and analyzed using a COULTER ${ }^{\circledR}$ EPICS $^{\circledR}$ XL $^{\text {TM }}$ Flow Cytometer.

Safety was assessed based on observed adverse events (AEs), clinical laboratory tests (hematology, biochemistry, and urinalysis), physical examination, results of 12-lead and 30-min continuous ECG, vital sign assessments, chest Xrays, and G-CSF antibody analysis.

\section{Statistical analysis}

The PD, PK, and safety populations were defined as described previously [4]. In the PK analysis, $\lambda_{z}$ and derivative parameters were not estimated for volunteers whose plasma concentration-time profiles in the terminal (log-linear) phase were not clearly defined with at least three quantifiable concentrations.

ANC $T_{\max }$ and $T_{\max }, \lambda_{z}$, and clearance for plasma concentration of G-CSF were summarized descriptively only. All other PK and PD parameters were $\log _{\mathrm{e}}$ transformed prior to statistical analysis and presented as geometric means, along with other summary statistics. Missing concentrations were deleted, resulting in an interpolation between the nearest two values. Outliers were identified using an outlier check ( $\mathrm{T}$ procedure). PK data were analyzed by non-compartmental methods using 
WinNonlin ${ }^{\circledR}$ (Pharsight ${ }^{\circledR}$ Corporation, Mountain View, CA, USA).

Bioequivalence was assessed for the primary and secondary endpoints using a mixed effects analysis of variance as described previously. If the $90 \%$ confidence interval (CI) for the ratio of 'test' to 'reference' means was completely within the conventional bioequivalence limits of 0.80-1.25, then bioequivalence was concluded.

A total of 48 evaluable volunteers were required for $80 \%$ power $(\alpha=0.05)$ to demonstrate bioequivalence between Hospira filgrastim and Amgen filgrastim, assuming a within-volunteer coefficient of variation of $23 \%$ and an equivalence range of $\pm 20 \%$ in the 'test' to 'reference' mean ratio for $\mathrm{ANC} \mathrm{AUC}_{0-\text { tlast }}$ at day 5 .

\section{Results}

Volunteer disposition

A total of 50 volunteers were enrolled: 24 into the $5-\mu \mathrm{g} / \mathrm{kg}$ dose group and 26 into the $10-\mu \mathrm{g} / \mathrm{kg}$ dose group (Fig. 1). Two volunteers in the $10-\mu \mathrm{g} / \mathrm{kg}$ dose group did not complete the study: one withdrew due to an AE (moderate musculoskeletal chest pain and mild back pain after completing the 5-day course of Amgen filgrastim and 3 days of Hospira filgrastim) and one withdrew for personal reasons (after completing the 5-day course of Amgen filgrastim). These volunteers were excluded from the PD and PK analyses. One further volunteer in the $10-\mu \mathrm{g} / \mathrm{kg}$ dose group was excluded from the PD analyses because of insufficient data (missing last time point). One additional volunteer in the $5-\mu \mathrm{g} / \mathrm{kg}$ dose group was excluded from the PK analyses for the same reason. All volunteers were evaluable for safety.

Investigators permitted several volunteers to take paracetamol for pain relief; however, this was not considered to affect study outcomes and therefore volunteers were not withdrawn. Baseline demographics were generally well matched between groups, although the proportion of Caucasian volunteers was slightly higher in the $5-\mu \mathrm{g} / \mathrm{kg}$ dose group than in the $10-\mu \mathrm{g} / \mathrm{kg}$ dose group, and accordingly the proportion of Black volunteers was slightly higher in the $10-\mu \mathrm{g} / \mathrm{kg}$ dose group than in the $5 \mu \mathrm{g} / \mathrm{kg}$ group (Table 1).

\section{Pharmacodynamics}

The primary PD endpoint (geometric mean $\mathrm{ANC} \mathrm{AUC}_{0-\text { tlast }}$ at day 5) was similar in volunteers who received Hospira filgrastim or Amgen filgrastim in both the $5-\mu \mathrm{g} / \mathrm{kg}$ (ratio of means, $0.98 ; 90 \% \mathrm{CI}, 0.92-1.05$ ) and $10-\mu \mathrm{g} / \mathrm{kg}$ (ratio of means, 0.97; 90\% CI, 0.93-1.01) dose groups (Table 2).
For both dose groups, $90 \%$ CIs were within the predefined range necessary to demonstrate bioequivalence of the two agents. The ANC profiles at both dose levels confirmed the similarity of Hospira filgrastim and Amgen filgrastim (Fig. 2). Secondary PD parameters were also generally similar between volunteers given Hospira filgrastim or Amgen filgrastim in both dose groups (Table 2). The only difference was that ANC $T_{\max }$ at day 5 in the $10-\mu \mathrm{g} / \mathrm{kg}$ dose group occurred slightly earlier with Hospira filgrastim than with Amgen filgrastim (geometric mean, 7.85 vs. 9.45 h, respectively). In the $5-\mu \mathrm{g} / \mathrm{kg}$ dose group, ANC $T_{\max }$ at day 5 was similar following administration of either Hospira filgrastim or Amgen filgrastim (geometric mean, 7.81 vs. $7.80 \mathrm{~h}$, respectively). Ninety percent CIs for ANC $C_{\max }$, ANC $C_{\text {min }}$, and CD34+ cell counts at day 5 were all within the predefined range required to demonstrate bioequivalence of the two agents.

Further analysis of CD34+ cell counts supported the bioequivalence of Hospira filgrastim and Amgen filgrastim. Geometric mean CD34+ cell counts remained similar with both agents, regardless of dose or time point (Fig. 3). The maximum mean CD34+ cell count (day 5) was 47.2 cells $/ \mu 1$ (95\% CI, 36.1-61.7) with Hospira filgrastim and 46.0 cells/ $\mu \mathrm{l}(95 \% \mathrm{CI}, 33.6-63.0)$ with Amgen filgrastim in the 5- $\mu \mathrm{g} /$ $\mathrm{kg}$ dose group. The maximum mean CD34+ cell counts were also similar with each agent in the $10-\mu \mathrm{g} / \mathrm{kg}$ dose group: 81.9 cells $/ \mu$ l (95\% CI, 64.5-104.0) with Hospira filgrastim and 77.5 cells/ $\mu$ l (95\% CI, 59.4-101.3) with Amgen filgrastim.

\section{Pharmacokinetics}

Following multiple dosing with $5 \mu \mathrm{g} / \mathrm{kg}$ s.c. Hospira filgrastim and Amgen filgrastim, the ratios of geometric means for $\mathrm{AUC}_{0-\text { tlast }}, \mathrm{AUC}_{0-24 \mathrm{~h}}, C_{\max }$ and $C_{\text {min }}$ at day 5 were 1.11 (90\% CI, 1.00-1.23), 1.11 (90\% CI, 1.00-1.23), 1.13 (90\% CI, 0.99-1.27), and 1.01 (90\% CI, 0.90-1.15), respectively. The $90 \% \mathrm{CIs}$ for $\mathrm{AUC}_{0-\text { tlast }}, \mathrm{AUC}_{0-24 \mathrm{~h}}$, and $C_{\text {min }}$ were within the range required to show bioequivalence of the two drugs. The upper CI for $C_{\max }$ was slightly above the predefined upper equivalence limit of 1.25 , but if outliers were excluded $(n=2), 90 \%$ CIs for $C_{\max }$ were shown to be within the predefined equivalence limits (ratio of means, $1.08 ; 90 \% \mathrm{CI}, 0.97-1.21)$. Mean $T_{\max }$ at day 5 occurred slightly earlier after administration of Amgen filgrastim $5 \mu \mathrm{g} / \mathrm{kg}$ compared with Hospira filgrastim $5 \mu \mathrm{g} /$ $\mathrm{kg}$ (3.83 vs. $4.21 \mathrm{~h}$, respectively).

Following multiple dosing with $10 \mu \mathrm{g} / \mathrm{kg}$ s.c. Hospira filgrastim and Amgen filgrastim, geometric mean ratios of 1.10 (90\% CI, 0.97-1.26), 1.10 (90\% CI, 0.97-1.26), 1.17 (90\% CI, 1.03-1.32), and 1.05 (90\% CI, 0.92-1.20) were reported for $\mathrm{AUC}_{0-\text { tlast }}, \mathrm{AUC}_{0-24 \mathrm{~h}}, C_{\max }$, and $C_{\text {min }}$ at day 5, respectively. Hospira filgrastim and Amgen 


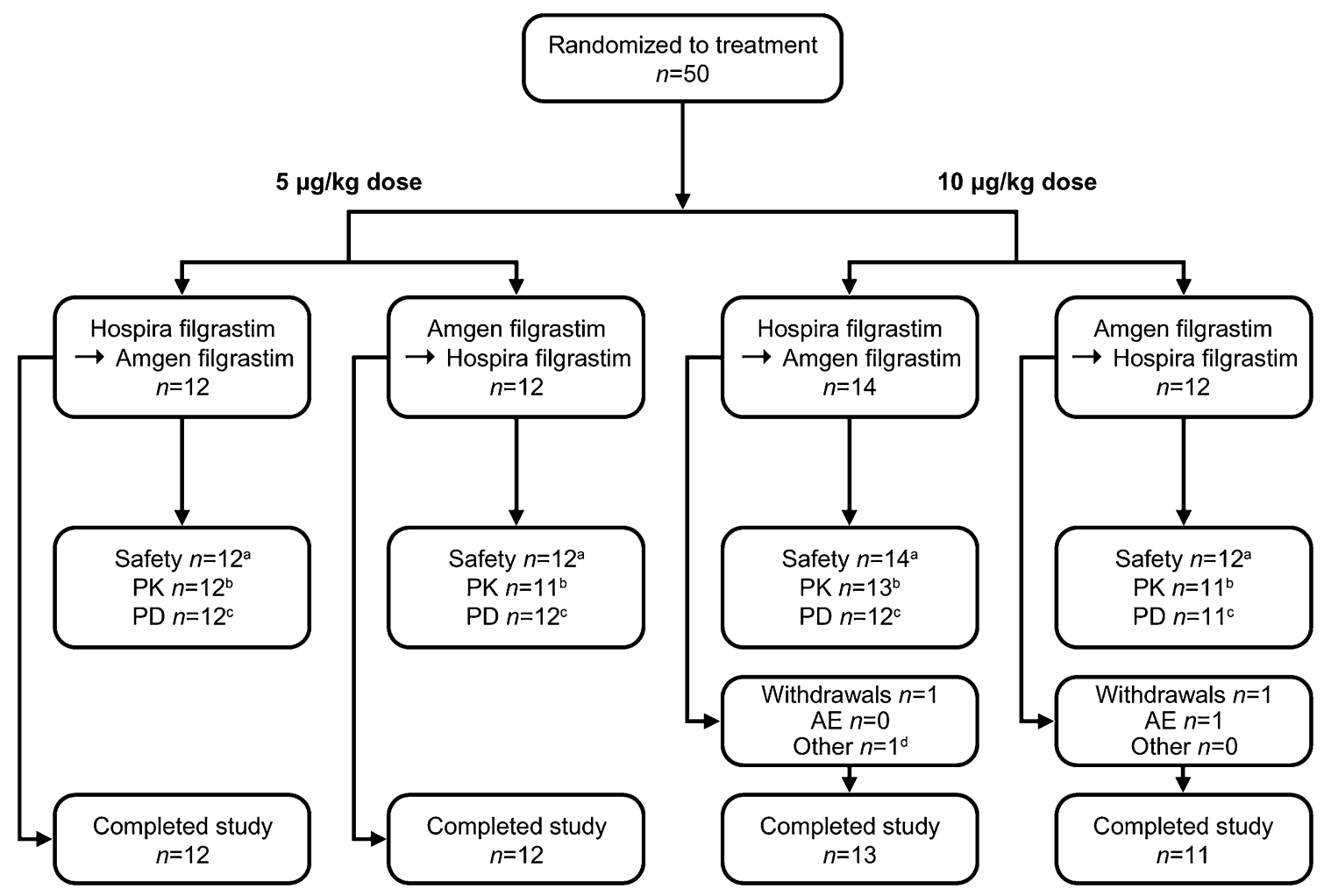

Fig. 1 Study design and volunteer disposition. Superscript a All volunteers who received $\geq 1$ dose of study medication; superscript $b$ all volunteers who completed the study with a sufficient number of quantifiable concentrations to warrant parameter estimation in both

assessment periods; superscript $c$ all volunteers for whom an evaluable PD parameter was obtained in both assessment periods; superscript $d$ volunteer withdrew

filgrastim were shown to be bioequivalent for $C_{\min }$, but not for $\mathrm{AUC}_{0-\text { tlast }}, \mathrm{AUC}_{0-24 \mathrm{~h}}$, and $C_{\text {max }}$, as the upper CIs for these parameters were slightly above the predefined upper equivalence limit. If outliers were excluded $(n=3)$, however, $90 \% \mathrm{CIs}$ for $\mathrm{AUC}_{0-\text { tlast }}$ and $\mathrm{AUC}_{0-24} \mathrm{~h}$ were shown to be within the predefined equivalence limits (for both parameters, ratio of means, 1.07; 90\% CI, 0.97-1.17). Mean $T_{\max }$ at day 5 occurred slightly later after administration of Amgen filgrastim $10 \mu \mathrm{g} / \mathrm{kg}$ compared with Hospira filgrastim $10 \mu \mathrm{g} / \mathrm{kg}$ (4.37 vs. $3.55 \mathrm{~h}$, respectively).

$\mathrm{AUC}_{0-\text { infinity }}$ and $T_{1 / 2}$ were not analyzed due to missing data.

Safety

The incidence of AEs in volunteers given Hospira filgrastim was slightly lower than that observed in volunteers given Amgen filgrastim in both the $5-\mu \mathrm{g} / \mathrm{kg}(79 \%$ vs. $83 \%$, respectively) and $10-\mu \mathrm{g} / \mathrm{kg}$ ( $77 \%$ vs. $92 \%$, respectively) dose groups (Table 3). The incidence of AEs related to the

Table 1 Baseline demographics

\begin{tabular}{lcc}
\hline Variable & $5 \mu \mathrm{g} / \mathrm{kg}$ dose $(n=24)$ & $10 \mu \mathrm{g} / \mathrm{kg}$ dose $(n=26)$ \\
\hline Male gender, $n(\%)$ & $15(62.5)$ & $16(61.5)$ \\
Mean age, years (SD) & $31.6(8.6)$ & $29.2(6.9)$ \\
Ethnicity, $n(\%)$ & & \\
Caucasian & $23(95.8)$ & $20(76.9)$ \\
Black & $1(4.2)$ & $5(19.2)$ \\
Asian & $0(0)$ & $0(0)$ \\
Other & $0(0)$ & $1(3.8)$ \\
Mean height, $\mathrm{cm}(\mathrm{SD})$ & $172.5(8.2)$ & $71.0(9.4)$ \\
Mean weight, $\mathrm{kg}(\mathrm{SD})$ & $75.8(11.4)$ & $24.0(12.8)$ \\
Mean BMI, $\mathrm{kg} / \mathrm{m}^{2}(\mathrm{SD})$ & $25.4(3.0)$ & $2.1)$ \\
\hline
\end{tabular}


Table 2 Summary of PD data

Geometric mean (range)

\begin{tabular}{|c|c|c|c|c|c|}
\hline & PD parameter & Hospira filgrastim & Amgen filgrastim & Ratio & $90 \% \mathrm{CI}$ \\
\hline & $5 \mu \mathrm{g} / \mathrm{kg}$ dose $(n=24)$ & & & & \\
\hline & ANC $\mathrm{AUC}_{0-\text { tlast}}, \mathrm{pg} \mathrm{h} / \mathrm{ml}$ & $1,633(918-2,633)$ & $1,660(696-2,535)$ & 0.98 & $0.92-1.05^{\mathrm{a}}$ \\
\hline & ANC $C_{\max }, \times 10^{9} \mathrm{~h} / 1$ & $36.09(24.12-52.19)$ & $35.66(18.14-58.17)$ & 1.01 & $0.96-1.07^{\mathrm{a}}$ \\
\hline & $\mathrm{ANC} C_{\min }, \times 10^{9} \mathrm{~h} / 1$ & $3.39(1.01-8.32)$ & $3.82(1.71-7.83)$ & 0.89 & $0.80-0.98^{\mathrm{a}}$ \\
\hline & ANC $T_{\max }, \mathrm{h}$ & $7.81(6.00-8.00)$ & $7.80(6.00-24.00)$ & - & - \\
\hline & CD34+ count, cells $/ \mu 1$ & $47.2(14.0-158.0)$ & $46.0(12.0-187.0)$ & 1.03 & $0.85-1.24^{\mathrm{a}}$ \\
\hline & $10 \mu \mathrm{g} / \mathrm{kg}$ dose $(n=23)$ & & & & \\
\hline & ANC $\mathrm{AUC}_{0-\text { tlast }}, \mathrm{pg} \mathrm{h} / \mathrm{ml}$ & $2,170(1,091-3,341)$ & $2,249(1,099-3,970)$ & 0.97 & $0.93-1.01^{\mathrm{a}}$ \\
\hline - not reported & ANC $C_{\max }, \times 10^{9} \mathrm{~h} / 1$ & $46.10(30.53-69.65)$ & $47.20(25.09-66.44)$ & 0.98 & $0.95-1.01^{\mathrm{a}}$ \\
\hline${ }^{\mathrm{a}}$ The $90 \%$ CI was within the & ANC $C_{\min }, \times 10^{9} \mathrm{~h} / 1$ & $3.01(1.86-6.11)$ & $3.24(1.69-4.90)$ & 0.93 & $0.83-1.04^{\mathrm{a}}$ \\
\hline predefined equivalence range of & $\mathrm{ANC} T_{\max }, \mathrm{h}$ & $7.85(4.00-24.00)$ & $9.45(6.00-24.07)$ & - & - \\
\hline $0.80-1.25$, demonstrating bioequi- & CD34+ count, cells $/ \mu 1$ & $82(19-184)$ & $78(28-232)$ & 1.06 & $0.90-1.24^{\mathrm{a}}$ \\
\hline
\end{tabular}

study drug was also slightly lower in volunteers who received Hospira filgrastim compared with those who received Amgen filgrastim in the $10-\mu \mathrm{g} / \mathrm{kg}$ dose group (77\% vs. $88 \%$, respectively), but was similar in both subsets of volunteers in $5-\mu \mathrm{g} / \mathrm{kg}$ dose group $(75 \%$ with both agents).
The most common AEs were back pain and headache (Table 3), most of which were related to the study drug. Only minor differences in AE profiles were observed between Hospira filgrastim and Amgen filgrastim (Table 3).

No serious AEs were reported and all AEs were mild or moderate in intensity, with the exception of two events:
Fig. 2 Mean ANC over time in subjects given Hospira filgrastim or Amgen filgrastim; a $5-\mu \mathrm{g} / \mathrm{kg}$ dose group and b $10-\mu \mathrm{g} / \mathrm{kg}$ dose group. Data shown are geometric means. Samples taken outside each schedule timepoint window have been excluded. $A N C$ absolute neutrophil count, $A U C_{0-\text { tlast }}$ area under the curve from time 0 to the last time point, $C I$ confidence interval

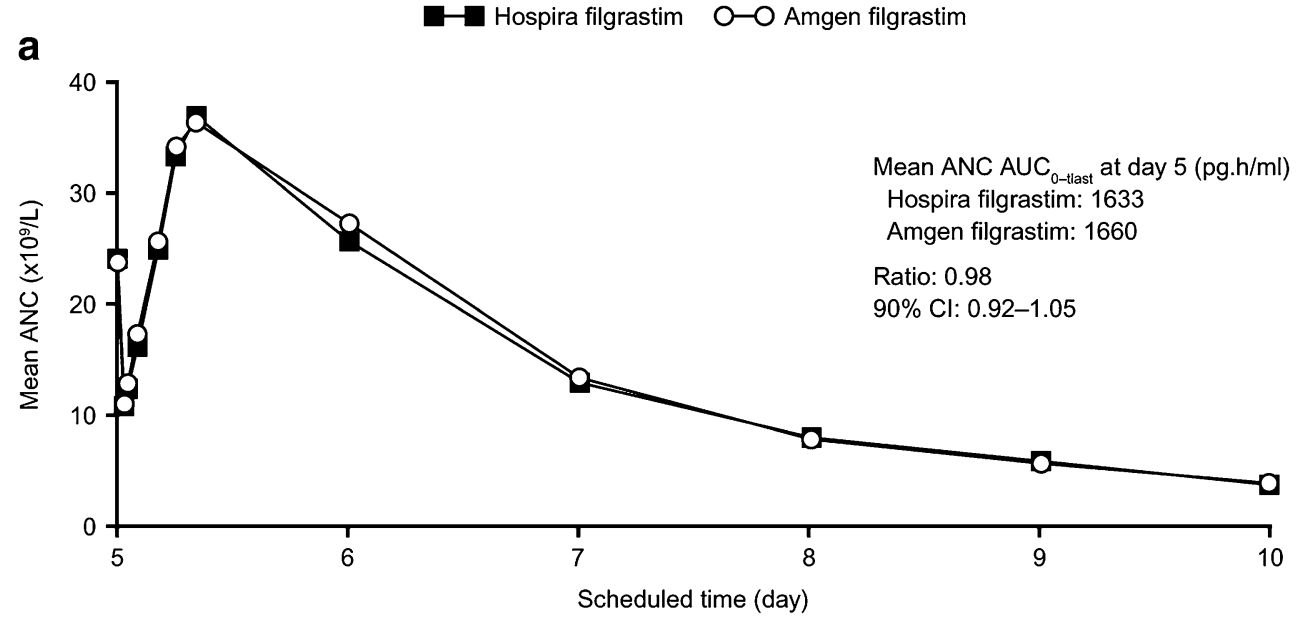

b

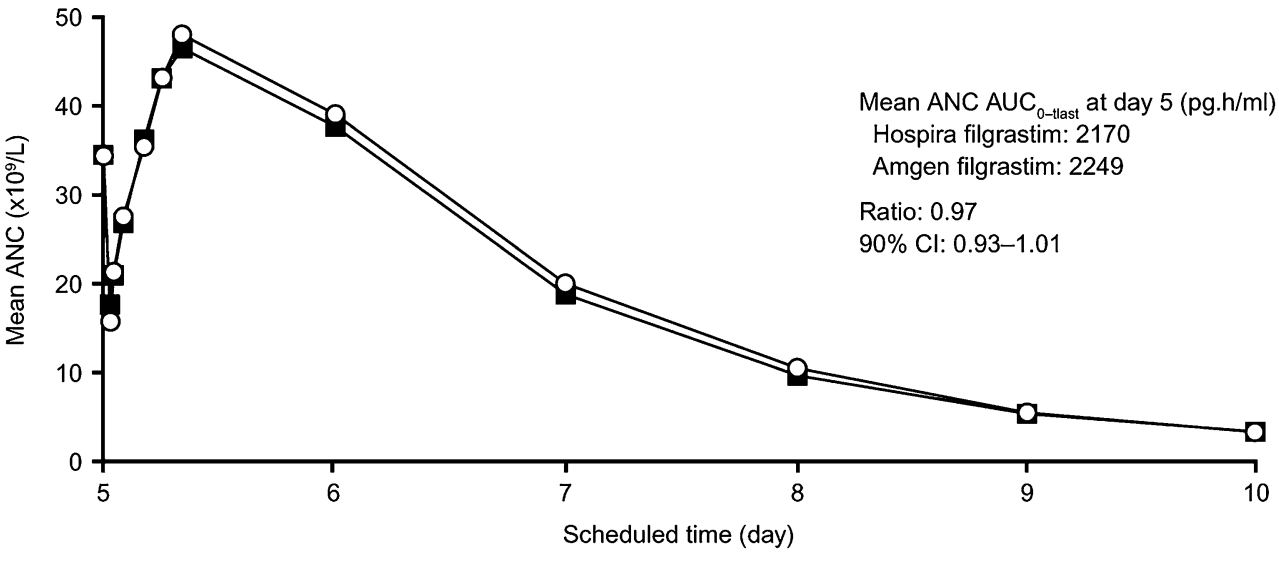


Fig. 3 Mean CD34+ cell count over time in subjects given Hospira filgrastim or Amgen filgrastim; a $5-\mu \mathrm{g} / \mathrm{kg}$ dose group and b $10-\mu \mathrm{g} / \mathrm{kg}$ dose group. Data shown are geometric mean values with lower and upper 95\% confidence intervals a

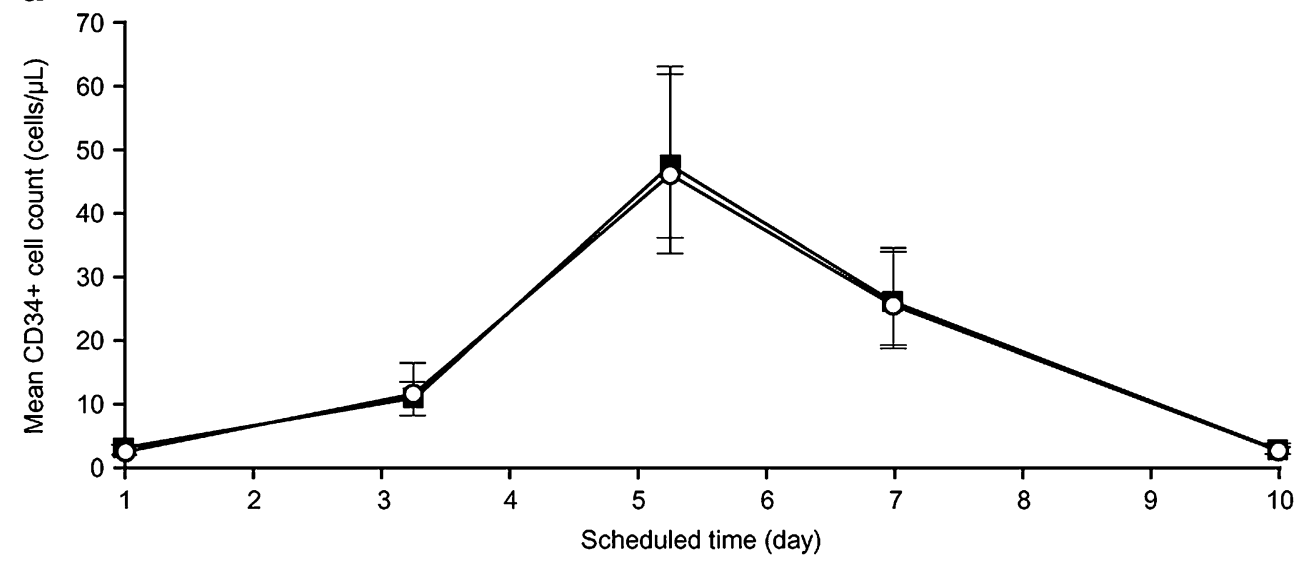

b

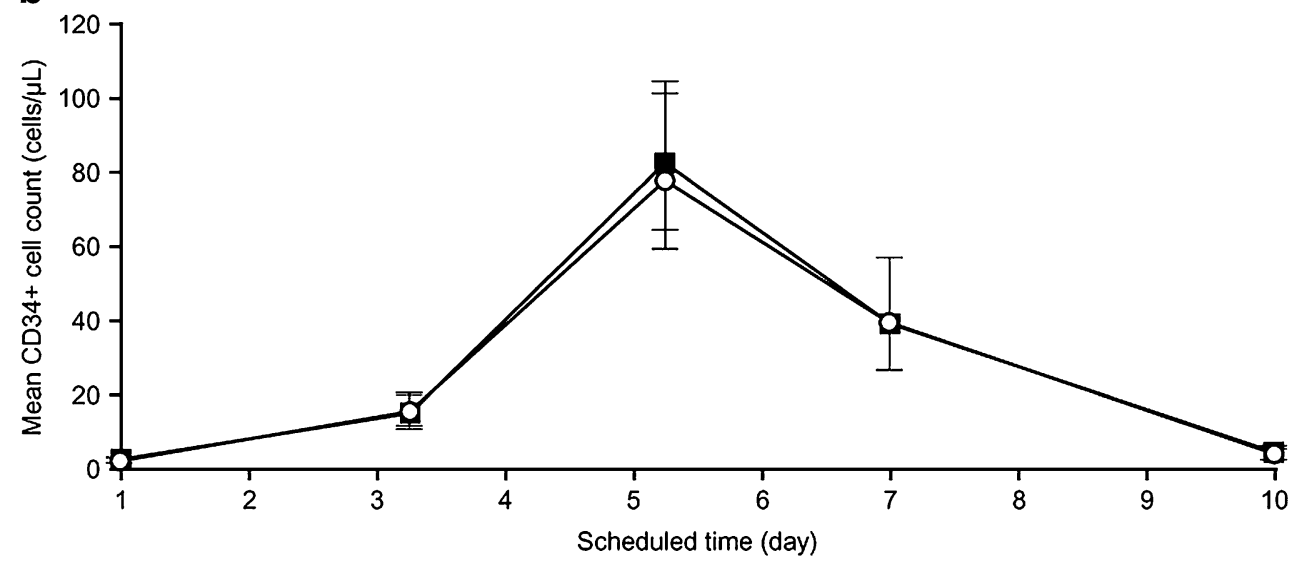

severe headache following administration of Amgen filgrastim $10 \mu \mathrm{g} / \mathrm{kg}$; and severe muscle spasms following administration of Hospira filgrastim $5 \mu \mathrm{g} / \mathrm{kg}$. Both of these AEs were considered to be related to study medication.

Laboratory data demonstrated: increases in lymphocyte, monocyte, eosinophil, basophil, and large unclassified cell counts; reductions in platelet counts; elevations in alkaline phosphatase, phosphate, lactate dehydrogenase and uric acid; and decreases in bilirubin. None of these changes were different between the study drugs. Two volunteers had clinically significant hematologic abnormalities (decreased/ increased platelet count) and a further six had biochemistry abnormalities (increased gamma glutamyl transferase [GGT; $n=3$ ]; alanine aminotransferase [ALT; $n=1$ ]; GGT and ALT $[n=1]$; and GGT, ALT, and lactate dehydgrogenase $[n=1])$. These changes occurred with both study drugs. No clinically significant changes in blood pressure, urinalysis, and physical examination were reported.

\section{Discussion}

According to guidelines issued by the European Medicines Agency (EMA), biosimilar medicinal products containing filgrastim should demonstrate comparability with Amgen filgrastim [10]. The EMA recommends a series of preclinical and clinical studies, including PD investigations in healthy volunteers, preferably at multiple-dose levels, with ANC as the primary endpoint and CD34+ cell count as a secondary parameter. The phase I PD study reported here was designed to fulfill EMA guidelines and forms part of the regulatory assessment for Hospira filgrastim.

Bioequivalence of the two filgrastims was demonstrated for all PD parameters tested (including $\mathrm{ANC} \mathrm{AUC}_{0-\text { tlast }}$ [primary endpoint]) at 5 or $10 \mu \mathrm{g} / \mathrm{kg}$ doses. The only difference between the two agents was that ANC $T_{\max }$ at day 5 in the $10-\mu \mathrm{g} / \mathrm{kg}$ dose group occurred slightly earlier with Hospira filgrastim than with Amgen filgrastim, but this is unlikely to have any clinical significance. Data on CD34+ cells demonstrate that Hospira filgrastim is equivalent to Amgen filgrastim for the mobilization of peripheral blood progenitor cells (PBPCs). This shows that Hospira filgrastim has potential for use as a growth factor to support autologous and allogeneic PBPC transplantation, indications where G-CSF has been used successfully for many years [11].

PK analyses largely supported the bioequivalence of Hospira filgrastim and Amgen filgrastim. However, for 
Table 3 Treatment-emergent AEs occurring in greater than five volunteers across all treatment groups

\begin{tabular}{|c|c|c|c|c|}
\hline \multirow[b]{2}{*}{$\mathrm{AE}$} & \multicolumn{2}{|l|}{$5 \mu \mathrm{g} / \mathrm{kg}$ dose, $n(\%)$} & \multicolumn{2}{|l|}{$10 \mu \mathrm{g} / \mathrm{kg}$ dose, $n(\%)$} \\
\hline & $\begin{array}{l}\text { Hospira filgrastim } \\
(n=20)\end{array}$ & $\begin{array}{l}\text { Amgen filgrastim } \\
(n=22)\end{array}$ & $\begin{array}{l}\text { Hospira filgrastim } \\
(n=26)\end{array}$ & $\begin{array}{l}\text { Amgen filgrastim } \\
(n=26)\end{array}$ \\
\hline Any event & $19(79.2)$ & $20(83.3)$ & $20(76.9)$ & $23(92.0)$ \\
\hline Gastrointestinal disorders & $5(20.8)$ & $6(25.0)$ & $3(11.5)$ & $6(24.0)$ \\
\hline Nausea & $2(8.3)$ & $3(12.5)$ & $3(11.5)$ & $2(8.0)$ \\
\hline General disorders and administration site conditions & $5(20.8)$ & $6(25.0)$ & $5(19.2)$ & $8(32.0)$ \\
\hline Chest pain & $2(8.3)$ & $4(16.7)$ & $2(7.7)$ & $3(12.0)$ \\
\hline Infections and infestations & $3(12.5)$ & $4(16.7)$ & $0(0)$ & $5(20.0)$ \\
\hline Nasopharyngitis & $2(8.3)$ & $3(12.5)$ & $0(0)$ & $4(16.0)$ \\
\hline Musculoskeletal and connective tissue disorders & $12(50.0)$ & $13(54.2)$ & $17(65.4)$ & $17(68.0)$ \\
\hline Arthralgia & $4(16.7)$ & $4(16.7)$ & $3(11.5)$ & $2(8.0)$ \\
\hline Back pain & $11(45.8)$ & $9(37.5)$ & $16(61.5)$ & $15(60.0)$ \\
\hline Neck pain & $1(4.2)$ & $2(8.3)$ & $4(15.4)$ & $4(16.0)$ \\
\hline Pain in extremity & $4(16.7)$ & $4(16.7)$ & $5(19.2)$ & $6(24.0)$ \\
\hline Nervous system disorders & $12(50.0)$ & $15(62.5)$ & $15(57.7)$ & $11(44.0)$ \\
\hline Headache & $11(45.8)$ & $14(58.3)$ & $14(53.8)$ & $11(44.0)$ \\
\hline Respiratory, thoracic, and mediastinal disorders & $7(29.2)$ & $4(16.7)$ & $3(11.5)$ & $7(28.0)$ \\
\hline Epistaxis & $2(8.3)$ & $2(8.3)$ & $0(0)$ & $3(12.0)$ \\
\hline Skin and s.c. tissue & $3(12.5)$ & $1(4.2)$ & $5(19.2)$ & $2(8.0)$ \\
\hline
\end{tabular}

several PK parameters, bioequivalence could only be concluded when outliers (as are commonly observed in studies of this kind $[12,13])$ were excluded. Bioequivalence could not be shown for $C_{\max }$ at day 5 , even when outliers were excluded. There was also some slight variability between the two agents in terms of $T_{\max }$ at day 5 at both dose levels.

While some PK parameters did not meet the prespecified bioequivalence limits for the $90 \%$ CI for the ratio of 'test' to 'reference' means, it should be considered that this study was primarily designed to evaluate PD characteristics and was not specifically designed to detect differences in PK. Furthermore, studies have indicated that there are PD-PK interactions between neutrophils and G-CSF, since neutrophils appear to contribute to G-CSF clearance [14]. This effect could have confounded the PK data, and it is therefore unsurprising that the bioequivalence of Hospira filgrastim and Amgen filgrastim was not demonstrated by all PK parameters.

Hospira filgrastim was generally well tolerated, with no unexpected toxicities. The AE profiles of Hospira filgrastim and Amgen filgrastim were comparable in terms of their nature and intensity, and similar to those reported previously for recombinant G-CSF in healthy volunteers [15]. The biochemical abnormalities were not considered to be related to study medication, but may instead have been caused by environmental stimuli or metabolic changes. However, mild reversible elevations in lactate dehydrogenase, alkaline phosphatase, and uric acid, and decreases in bilirubin, have been reported previously with G-CSF $[8,16]$. The general hematopoietic effect of G-CSF on lymphocytes, monocytes, basophils, and eosinophils is also well documented in the literature [15, 1719].

In conclusion, this study builds on evidence from the phase I PK study (previously reported in this journal) to support the further clinical evaluation of Hospira filgrastim. In line with this, results were recently reported from a large, randomized, double-blind, phase III trial of Hospira filgrastim versus Amgen filgrastim in patients receiving myelosuppressive chemotherapy for the treatment of breast cancer [20]. Data from these studies indicate that Hospira filgrastim is well tolerated and may provide a clinically effective alternative to Amgen filgrastim for a range of indications in which G-CSF is routinely used.

Acknowledgments The authors kindly acknowledge the contribution of Hannah FitzGibbon and Nigel C Eastmond from GeoMed for medical writing assistance in the preparation of this manuscript, with financial support from Hospira.

Authorship and disclosures CW contributed to the study design, the interpretation of the data and the consideration of its relevance to clinical practice. MB contributed to the interpretation of the data and the consideration of its relevance to clinical practice. SM was the principal investigator and had overall responsibility for the conduct of 
the study. RC is the Clinical Program Director at Hospira UK Ltd. All authors critically reviewed each draft of the manuscript prior to submission. CW and MB have consultancy agreements with Hospira UK Ltd, and SM is the Medical Director of Operations at Quotient Clinical. No other conflicts of interest were reported.

Open Access This article is distributed under the terms of the Creative Commons Attribution Noncommercial License which permits any noncommercial use, distribution, and reproduction in any medium, provided the original author(s) and source are credited.

\section{References}

1. Aapro MS, Cameron DA, Pettengell R, Bohlius J, Crawford J, Ellis M, Kearney N, Lyman GH, Tjan-Heijnen VC, Walewski J, Weber DC, Zielinski C (2006) EORTC guidelines for the use of granulocyte-colony stimulating factor to reduce the incidence of chemotherapy-induced febrile neutropenia in adult patients with lymphomas and solid tumours. Eur J Cancer 42:2433-2453

2. Dale DC (2002) Colony-stimulating factors for the management of neutropenia in cancer patients. Drugs 62(Suppl 1):1-15

3. Welte K, Gabrilove J, Bronchud MH, Platzer E, Morstyn G (1996) Filgrastim (r-metHuG-CSF): the first 10 years. Blood 88:1907-1929

4. Waller CF, Bronchud M, Mair S, Challand R (2010) Pharmacokinetic profiles of a biosimilar filgrastim and Amgen filgrastim: results from a randomized, phase I trial. Ann Hematol [epub ahead of print]

5. Duhrsen U, Villeval JL, Boyd J, Kannourakis G, Morstyn G, Metcalf D (1988) Effects of recombinant human granulocyte colony-stimulating factor on hematopoietic progenitor cells in cancer patients. Blood 72:2074-2081

6. Martinez C, Urbano-Ispizua A, Marin P, Merino A, Rovira M, Carreras E, Montserrat E (1999) Efficacy and toxicity of a highdose G-CSF schedule for peripheral blood progenitor cell mobilization in healthy donors. Bone Marrow Transplant 24:1273-1278

7. Souza LM, Boone TC, Gabrilove J, Lai PH, Zsebo KM, Murdock DC, Chazin VR, Bruszewski J, Lu H, Chen KK (1986) Recombinant human granulocyte colony-stimulating factor: effects on normal and leukemic myeloid cells. Science 232:61-65

8. Stroncek DF, Clay ME, Petzoldt ML, Smith J, Jaszcz W, Oldham FB, McCullough J (1996) Treatment of normal individuals with granulocyte-colony-stimulating factor: donor experiences and the effects on peripheral blood CD34+ cell counts and on the collection of peripheral blood stem cells. Transfusion 36:601-610

9. Welte K, Bonilla MA, Gillio AP, Boone TC, Potter GK, Gabrilove J, Moore MAS, O'Reilly J, Souza LM (1987) Recombinant human granulocyte colony-stimulating factor. J Exp Med 165:941-948

10. Committee for Medicinal Products for Human Use (CHMP) (2009) Annex to guideline on similar biological medicinal products containing biotechnology-derived proteins as active substance: non-clinical and clinical issues. Guidance on similar medicinal products containing recombinant granulocyte-colony stimulating factor. Available at www.emea.europa.eu/pdfs/human/ biosimilar/3132905en_pdf. Accessed 28 Jan 2009

11. Siena S, Schiavo R, Pedrazzoli P, Carlo-Stella C (2000) Therapeutic relevance of CD34 cell dose in blood cell transplantation for cancer therapy. J Clin Oncol 18:1360-1377

12. Chow SC, Tse SK (1990) Outlier detection in bioavailability/ bioequivalence studies. Stat Med 9:549-558

13. Liao JJ (2007) A new approach for outliers in a bioavailability/ bioequivalence study. J Biopharm Stat 17:393-405

14. Kuwabara T, Kobayashi S, Sugiyama Y (1996) Pharmacokinetics and pharmacodynamics of a recombinant human granulocyte colony-stimulating factor. Drug Metab Rev 28:625-658

15. Anderlini P (2009) Effects and safety of granulocyte colonystimulating factor in healthy volunteers. Curr Opin Hematol 16:35-40

16. Nguyen YK (1994) Granulocyte colony stimulating factor. J Fla Med Assoc 81:467-469

17. Fernandez-Varon E, Villamayor L (2007) Granulocyte and granulocyte macrophage colony-stimulating factors as therapy in human and veterinary medicine. Vet J 174:33-41

18. Hirai K, Morita Y, Miyamoto T (1992) Hemopoietic growth factors regulate basophil function and viability. Immunol Ser 57:587-600

19. Rutella S, Rumi C, Sica S, Leone G (1999) Recombinant human granulocyte colony-stimulating factor (rHuG-CSF): effects on lymphocyte phenotype and function. J Interferon Cytokine Res 19:989-994

20. Waller CF, Semiglazov VF, Chan S, Challand R (2009) Biosimilar filgrastim is an effective primary prophylactic therapy for neutropenia in patients (pts) receiving doxorubicin and docetaxel (AT) for breast cancer (BC). Poster presentation at the joint ECCO 15 and 34th ESMO Multidisciplinary Congress; Abstract E15-1238 